\title{
An Integrated Methodology for the Identification of Agricultural Districts: a Case Study in Calabria
}

\author{
Claudio Marcianò ${ }^{1, a}$, Paolo Careri ${ }^{1, b}$ and Enrico D'Angelillo ${ }^{2, c}$ \\ ${ }^{1}$ Agraria Department, Mediterranean University of Reggio Calabria, \\ Feo de Vito, 89122 Reggio Calabria, Italy \\ ${ }^{2}$ ISRI, Institute of Industrial Relations, Via Monte delle Gioie, 00199 Roma, Italy \\ aclaudio.marciano@unirc.it, ${ }^{b}$ paolo.careri@unirc.it, ce.dangelillo@isri.rm.it
}

Keywords: Rural Districts, Agro-Food Districts, Integrated Rural Development.

\begin{abstract}
The reorganization processes within the rural areas have generated the most modern networks of relationships among agriculture, industry and service sector. Therefore, in the last decades the analysis of such areas has dealt with theories concerning agglomeration economies. In this perspective, the new protagonist is a multifunctional agriculture which has led to an increase in the number of actors present in the processes of planning and implementation of European rural policies. In this way, it has been possible to generate forms of local governance such as the Local Action Groups (LAGs), within the Leader Initiative, or other forms of governance according to the several adopted instruments of integrated planning. In Italy, inspired by the pattern of industrial districts, the Legislative Decree 228/2001 has regulated agricultural districts. The study proposes a methodology to check the vocationality of a large area in the province of Reggio Calabria towards the institution of an agricultural district. The results of the research show a homogeneous and cohesive area around the agro-food sector, above all in terms of employment.
\end{abstract}

\section{Introduction}

During the last decades, inside the most modern rural areas, it has been possible the beginning of innovative processes of socio-economic re-organization and of resource re-allocation which have generated nets of relations between agriculture, industry and tertiary. In a rural space, in which the agriculture sector is dominant, the non-farm activities present organizational forms of production appearing integrated and marked out by a strong territorial rooting $[1,2]$. The transformation of the rural space, in which the agricultural sector has achieved a new multifunctional role, has led to the progressive growing of the number of actors involved in the planning and the carrying out of European rural policies which, decentralizing themselves, have allowed to experience new forms of local governance. Some examples are offered by those realised by the Local Action Groups (LAGS) within the EU Leader Initiative and within the Rural Development Programmes (RDP), and by those related to the different instruments of integrated planning. At this purpose, Rural Districts (RD) and Quality Agro-Food Districts (DAQ), represent two innovative typologies of governance and of integrated territorial planning introduced by the Law Decree no. 228 of 2001. The norm recognition of such Agricultural Districts and the potential advantages derived from their institution, generate in different rural areas a strong interest towards them [3].

According to national law directions, another instrument, which is generally assimilated to productive districts, is the net of enterprises, based on the "network contract": actually, it "marks a point of discontinuity rather than the district model, losing the territorial connotation, the local dimension, the idea of the common effort of local, public and private actors" [4]. At European level, Italian Districts can be compared to Clusters, considered as "groups of similar and related firms in a defined geographic area that share common strategies for increasing their own growth and competitiveness", and that constitute a juridical subject with independent coordination and management activities. Dealing with "Poles" or Clusters", the new European Agricultural Fund for Rural Development Regulation (EAFRD) no 1305/2013 gives clear references about cooperation 
encouraging operators of agricultural sector to share experiences and develop skills, services and new and specialized products" [5]. This study proposes a methodological approach aimed at verifying the vocationality of an area of 43 Municipalities in the Tyrrhenian side of the province of Reggio Calabria towards the institution of an Agricultural District.

\section{Methodology}

An Agricultural District represents the result of a convergence of interests and purposes shared by the public and private components of a territory, characterized by a homogeneous productive structure and intense socio-economic phenomena. Therefore, it becomes a moment of agreement between the needs of the local community and the instruments of integrated planning. In literature, the methodologies adopted for the identification of the Agricultural Districts in Italy are not univocal and they can be traced back to top-down or bottom-up approaches. In particular, the first approach aims at identifying homogeneous areas as potential districts. [6,7,8]. Instead, in the bottom-up approach the starting point is opposite: it consists in choosing the area and in checking the vocationality of its agricultural and rural systems for an eventual candidacy as a District [9].

The proposed methodology integrates different typologies of analysis (Fig. 1) and foresees, as first steps of general and specific analysis, the socio-economic and territorial investigation of the chosen area, followed by an analysis of the social capital activated through the main experiences of integrated planning. The second step, aimed at the District hypothesis, foresees the quantitative characterization of agricultural and rural systems, the qualitative characterization of rural atmosphere and the definition of a process for the candidature of the examined area as a District, also outlining a possible model of governance.

The first step of general analysis includes the territorial analysis and the socio-economic dynamics of the chosen area. Subsequently, the specific analysis is based on the social capital defined as a net of relations linking both individuals and groups, whose interaction promotes the pursuit of goals that could not be reached by the individual if not at a higher cost. The approach refers to the theoretical model developed by Coleman [10] and to its integration with the studies on social nets proposed by Granovetter [11]. The research proposes a general analysis and an analysis of the social capital activated through different forms of integrated planning in the Tyrrhenian side of the province of Reggio Calabria. Carried out through the Social Network Analysis, the study wants to highlight the role and features of the socio-economic partnerships involved in the different typologies of integrated plans implemented in the area. They are based on local socio-economic partnerships and can be considered as proto-district actions, because they encourage processes of local governance potentially evolvable over time into more complex forms such as districts. The analysis wants to point out, within the various types of integrated plans, those with the greatest impact in terms of social capital development in the area.

The analysis aiming at the district hypothesis is carried out through a quantitative analysis of the agricultural and rural systems and a qualitative analysis of the rural atmosphere. The quantitative analysis foresees the definition of a set of indicators and their selection on the basis of their significance. In order to reach a mapping proposal, it has been necessary to distinguish two groups of Municipalities, termed respectively as "medium-high vocationality" and as "medium-low vocationality".

The qualitative analysis measures a distinctive feature of the district mechanism, the so-called "industrial atmosphere" [12], which, applied to farming and rural areas, is termed "rural atmosphere", becoming a dimension which is re-adapted and decomposed in different variables. These last ones are inserted in a specific questionnaire including different sectors of activities and administered to a sample of public and private actors of the examined area. The proposed methodology requires that each interviewed subject gives his own opinion on each variable according to a scale, the intensity of which varies from one to five. With regard to the identification of variables, they include some features dealing with modern rurality such as local skills, farm diversification, the sense of belonging 
to the territory, cooperative atmosphere, the degree of trust, the characteristics of the material and immaterial institutional environment, related to the technical assistance services in the area, and the level of confidence in institutions.

About the selection of the interviewed subjects and stakeholders of the territory, four main categories have been identified: farms, experts, category associations and Public Authorities. The structuring of the questionnaire has foreseen different sections such as the information referred to productive activities. With respect to work, occupational aspects, professional mobility and levels of job specialization have been examined; at last, typical aspects of rural areas, such as tradition, cooperation, the tendency to form associations and the degree of trust have been analysed. The remaining sections of the questionnaire are related to the information about the level of innovation and, therefore, the role of technical assistance, and about the public intervention and credit grant.

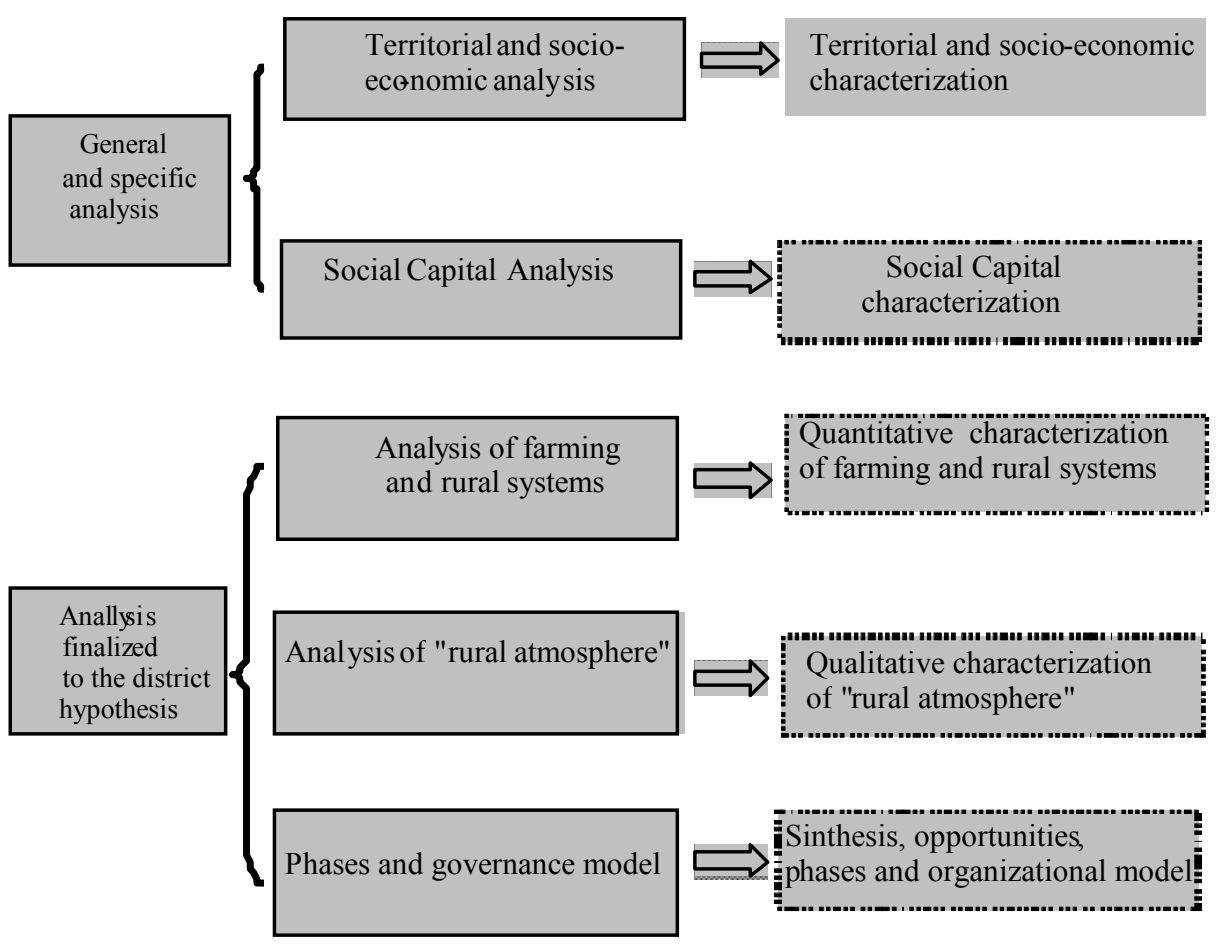

Legend:

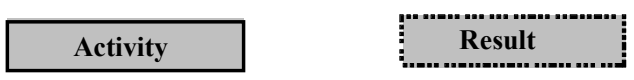

Fig. 1- Methodological phases

A last step of analysis has regarded the definition of the district process and the governance model.

The districts foresee an instrument of governance in which it becomes important to establish who has the right competence and on what, avoiding the superimposition with other levels of governance [13]. Indeed, the risk of "superimpositions" is felt by Public Authorities, in particular by Regions, which are responsible for recognising a district. The same risk is felt by the private subjects and associations of a territory interested to the candidacy as a district. The outlined methodological approach foresees a final paragraph which, after analyzing the main problems and opportunities annexed to the realization of a rural district, synthesizes the results obtained in the applicative part.

Moreover, it is proposed a model of governance for district and the description of the work steps which could be necessary to promote at the Region the candidature as QAFD or RD. A last step of analysis has regarded the definition of the district process and the governance model. The districts foresee an instrument of governance in which it becomes important to establish who has the right competence and on what, avoiding the superimposition with other levels of governance [13]. Indeed, 
the risk of "superimpositions" is felt by Public Authorities, in particular by Regions, which are responsible for recognising a district. The same risk is felt by the private subjects and associations of a territory interested to the candidacy as a district. The outlined methodological approach foresees a final paragraph which, after analyzing the main problems and opportunities annexed to the realization of a rural district, synthesizes the results obtained in the applicative part. Moreover, it is proposed a model of governance for district and the description of the work steps which could be necessary to promote at the Region the candidature as QAFD or RD.

\section{Results}

Synthesis of the results of the general and specific analysis

The Tyrrhenian side of the province of Reggio Calabria in 2011 recorded a population of 204.191 inhabitants. The results of the socio-economic and territorial analysis highlight a phenomenon of depopulation which appears more marked in the internal mountain areas. In terms of production, the data referred to the relation between SAU and SAT give evidence of a meaningful use of the farming surface, characterized by the dominance of the wooden agrarian cultivations. Within such cultivations, the olive-tree shows a strong presence with a relevant weigh equal to $70,29 \%$. Instead, the surface covered by woods and poplar-trees, represents $29,70 \%$ of the SAT. By analyzing the structural aspect of firms, generally they reveal a high level of fragmentation and a management form corresponding to family-run businesses. The meaningful value of the index of agricultural work intensity highlights how the human work is an important component of the productive process in agriculture. In terms of employment, the primary sector absorbs almost a quarter of the total number of employees.

Even if in the area the farming productive system still has an important weight, it is possible to observe the presence of other extra-farming productive activities - both in the manufacturing industry and in the service sector - deriving from small and medium enterprises. Indeed, inside the industrial sector, manufacturing activities assume a major weight, both in terms of employees, with $59,02 \%$, and local units, with $62,21 \%$ on the total. The tertiary sector stands out for the high employment concentration $(58,18 \%)$ and the high incidence of the local units on the total, as marked by the high rate of tertiarization. About the importance of the extra-farming activities in the area, extremely significant is the value of the configuration index of craft enterprises (a quarter of the local units), revealing a strong link with the primary sector, a fundamental requirement for the district mechanism. In addition, from the interpretation of statistical data, it is clear that the area Leader presents a cohesive system around olive-growing, oil-making and citrus sectors, combined with a uniformly widespread rurality.

The specific analysis has compared the main typologies of the Integrated Plans activated in the area Leader + for the assessment of the relational capital and its distribution among the subjects involved in the different experiences of integrated planning. The analysis of the active partnerships in the examined area has studied the capacity and the interest of the local actors in organizing themselves in forms of Socio-economic Partnerships which, representing the interests of the area, have played a key-role in resource planning. Developed through the different typologies of the Integrated Plans realised in the area, the study on the relational capital has interested the local partnerships through an analysis of social network carried out in the area of the Plan elaborated within the EU Leader+ Initiative, which included 44 Municipalities and a partnership of more than 100 public and private subjects [14]. Inside this territory, in the same period, other 7 Integrated Plans were involving so many partnerships and, more in particular, 4 Integrated Plans for the Rural Areas (PIAR) and 3 Territorial Integrated Projects (PIT). The analysis of the composition and the width of the partnerships which have promoted the integrated plans of the area marks a consistent quantitative and qualitative variability of the involved subjects. The results highlight that in the area, the most decentralized local model of governance, flexible to the local needs, has been proposed within the Leader Plus field. In such a Community initiative, the governance system foresees a strong involvement of the territory 
both in the planning and implementation steps. The Leader governance has financial autonomy and the role of the public administrations, at a regional, state and community level, is limited to the control and it is monitored by the regional Managing Authority. The study underlines the central role the PSL has within the different experiences of the integrated planning activated in the territory (Fig. 2). Coming out from an intense activity of animation, the representativeness of the partnership is so tangible that the role carried out by the Local Action Group in the territory has been the main instrument of activation of the social capital in the interested area, being actively involved in most of Integrated Plans. From the analysis about centrality carried out for the different typologies of the integrated plans under examination, it comes out the high level of centrality of the Leader+ through the implementation of the Local Development Plan "Reggino Versante Tirrenico", both for the value of the network level of affiliations and for the value of the one-modal level of the events overlapping.

The analysis also shows the evolution of the partnerships involved in integrated planning in the period 2007-2013 and how, in absence of the Leader Local Development Plans, several actors of the network would have been left isolated [15].

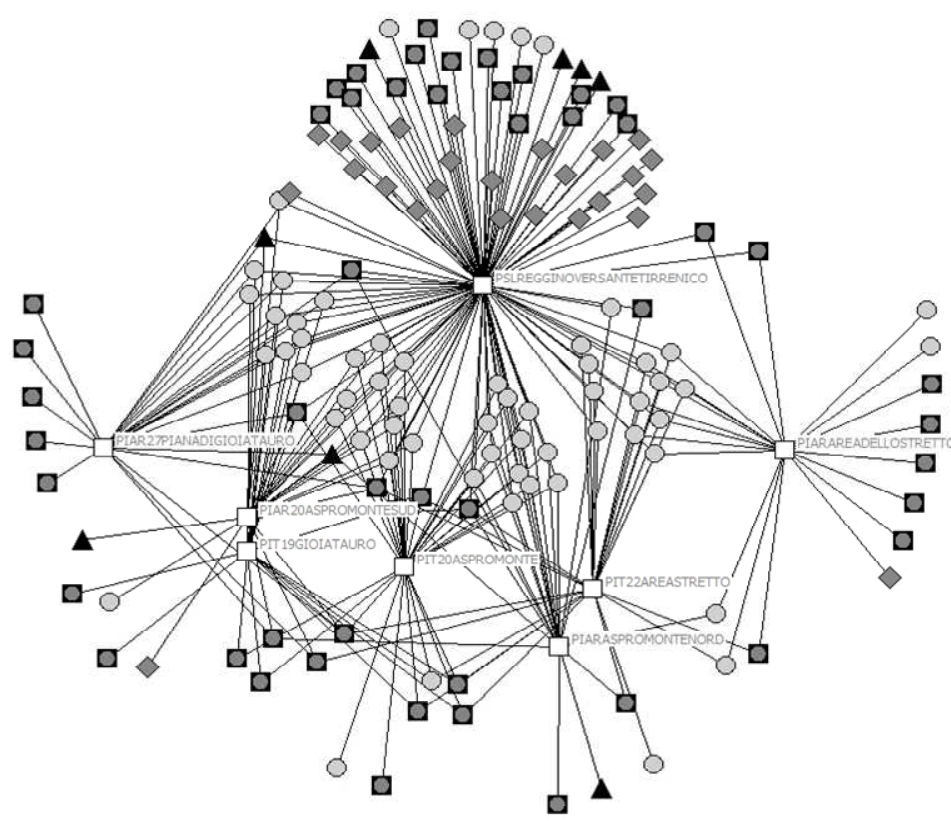

Integrated Development Plans

Public bodies

$\diamond$ Private entrepeuners

D Private Organizations

$\Delta$ Technicians

Fig. 2 - The Affiliation Network of the Integrated Plans

\section{- Synthesis of the results obtained from the analysis finalized to a district hypothesis}

The analysis has been carried out through a quantitative assessment of the "vocationality" of the farming and rural systems of the examined area, for a possible candidature as an Agricultural District (DR or QAFD). The phase dealing with the quantitative analysis of the farming and rural systems, already described in the methodological paragraph, has been realised by adopting suitable indicators already used in other researches and in different regional laws; the elaboration of the selected indexes has been carried out on the total of the area and, for each index, it has been computed the number of the municipalities assuming meaningful values with respect to the regional and provincial average.

The results of the proposed mapping, visible in figure 3, show a good cohesion around the farming and agro-food sectors, above all in terms of employment. It is important to highlight that the mapping, basing on quantitative data, does not clarify some fundamental aspects for the district hypothesis, referring to the relations system existing inside the area, analyzed within the study on the relational capital in the area itself and on the qualitative analysis of the rural atmosphere. Finally, in the mapping it is evident that the Municipality of Cardeto is not contiguous with respect to the other Municipalities belonging to the area. For this reason, during the planning period 2007-2013, Cardeto has been associated to the Municipalities of the Grecanic Area of the Reggino Ionian side. 
The qualitative analysis of the rural atmosphere defines the distinctive elements of the "district atmosphere", evaluating the opportunity to rediscover its features in the farming field. The intensity of such a quality has been measured through a direct enquiry of qualitative type which measures some components of the rural atmosphere, through the elementary factorization of the theoretical model, graphically represented by a polygon the vertices of which are made up of the elements of the above-mentioned decomposition (Fig. 4).
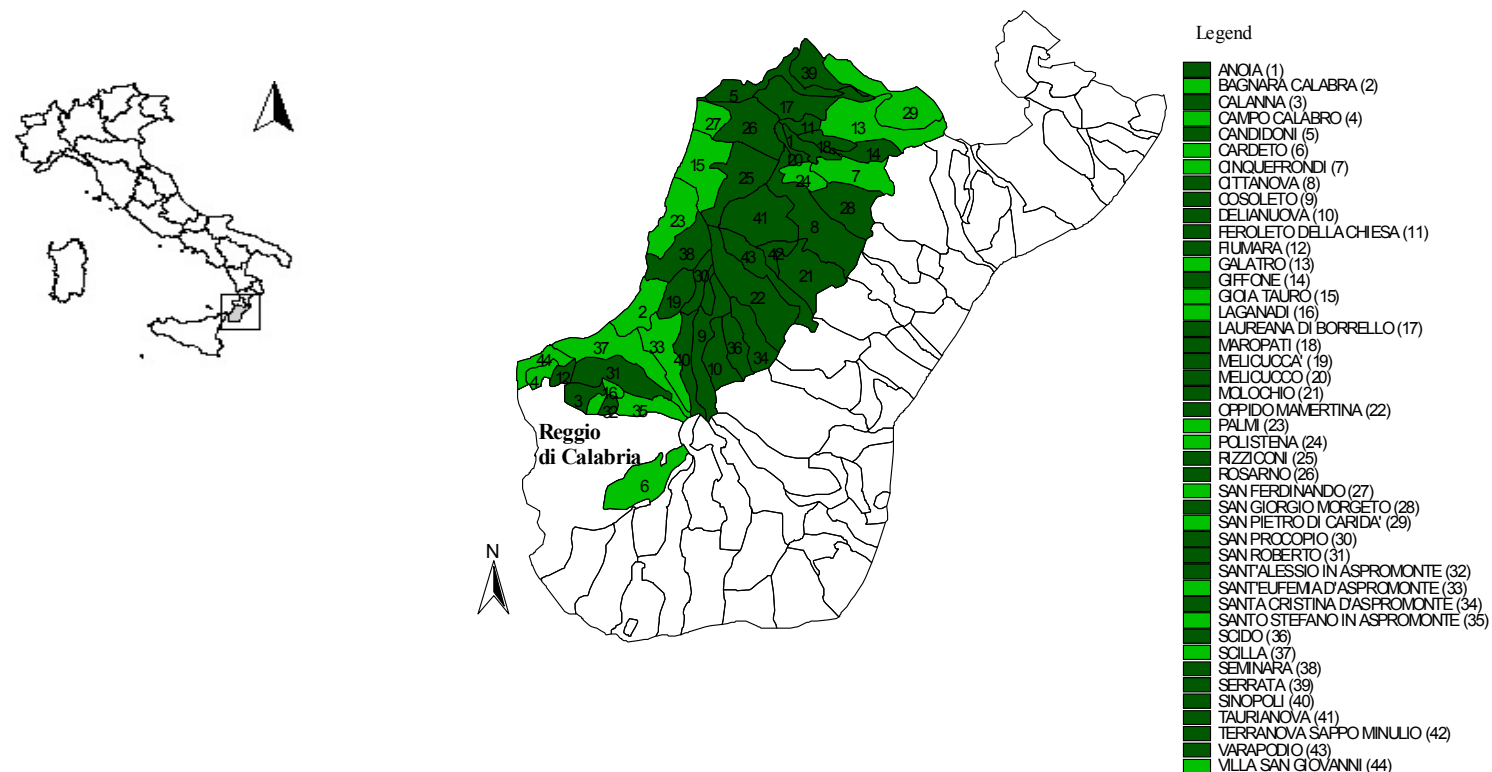

Legend :

Municipalities at a medium-high vocation

Municipalities at a medium-low vocation

Fig. 3- The results of the quantitative characterization of farming and rural systems
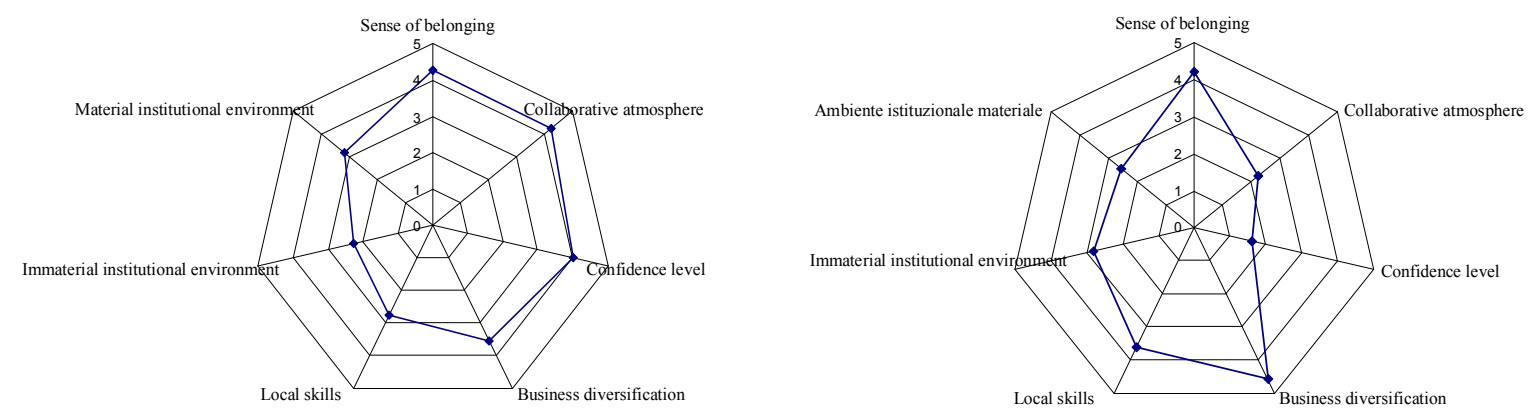

1

2
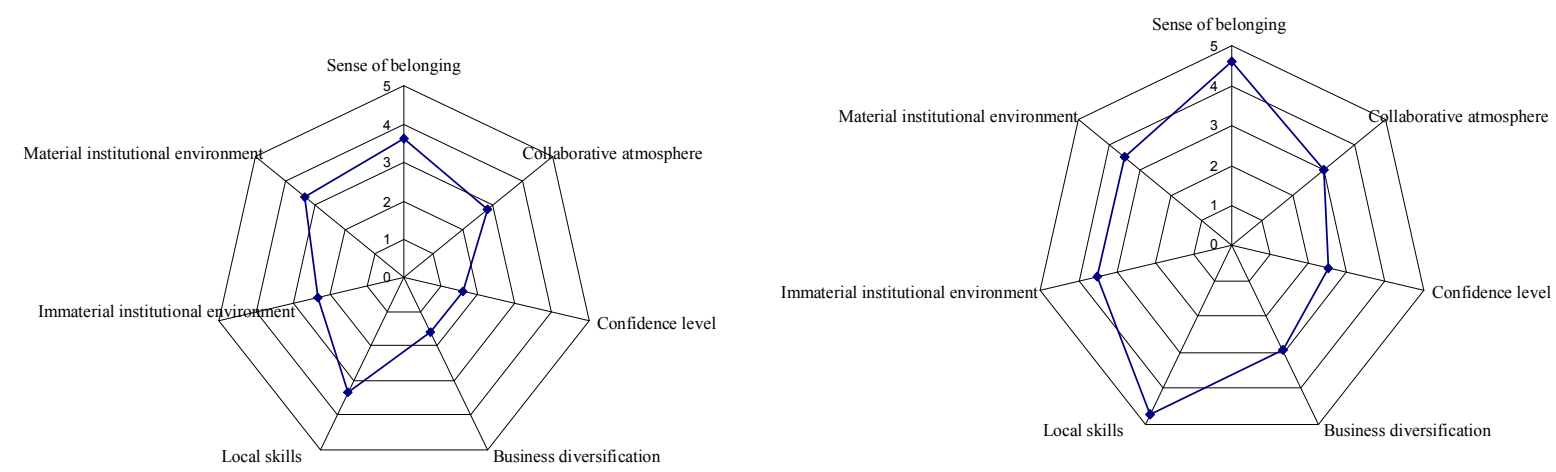

4

Figure 4 - Assessment of rural atmosphere for the privileged witnesses

(1- farms; 2- experts; 3-trade associations; 4-public authorities). 
By analyzing the administered questionnaire, the answers given by the different categories of privileged witnesses (farms, category associations, experts, public authorities) must be considered positively, with respect to the absolute requirements qualifying a district. Indeed, for all the categories, it appears a high sense of belonging to the territory, even if it is evident a concern by the entrepreneurs about the continuation of the activity for the reduction of EU financial aids. Moreover, if from one hand the consortium and association forms are considered as a possible form of survival, on the other hand they are seen as a danger for the territorial identity". A second aspect characterizing the area for a district hypothesis is related to the importance of the primary sector in social and economic relations; the inhabitants of the area have relationships with each other thanks to a given structure, common values, experiences and traditions, deriving and depending on the primary sector.

As for the cooperative atmosphere, it is necessary to take into account the different opinions of the various groups. Considering the entrepreneurs, the results show a high tendency to let the information circulate, because it is cheaper rather than consulting an expert. Different is the opinion of associations and professionals who, in spite of recognizing the tendency to form associations, think that in the district area such a variable is less present. Also about the level of trust, according to the interviewed subjects, it is possible to catch some differences. Among the entrepreneurs, during negotiations there is a sense of trust derived from the long-term rooting of relationships. On the contrary, the same attitude is not evident towards institutions that, according to the interviewed, very often neglect operators' exigencies. Even experts and associations believe that too much bureaucracy could represent an obstacle to a more direct relation. The opinion given on the level of technical assistance, common to all the interviewed, shows that against a not satisfying service, the idea of a major investment in the research, innovation and experimentation activity could offer remarkable margins of improvement in such direction.

Concerning the governance model of the Agricultural District, it has been hypothesized the constitution of a dual governance, in conformity with the model foreseen by regional regulations. Such a model foresees the setting up of a Company of District, made up of private subjects (entrepreneurs), and a Committee of District, made up by the institutional subjects finding themselves within the territorial configuration of the proposed District. Among the advantages of such a model, there is certainly the new role got by the privates, who not only represent the engine of the District, because actors of the interventions, but also because able to express their own opinion about the strategic aspect, having to draw up the del Plan of District.

\section{Conclusions}

As regards the methodologies adopted for the identification of districts in agriculture, it is evident in literature a prevalence of quantitative approaches rather than the qualitative or mixed ones. The approach described in this study combines different methods of analysis. The results show a good cohesion around the agro-food sector, above all in terms of employment and of belonging to the territory. With respect to the possibilities offered by the new Common Strategic Framework 2014-2020 of the European Structural and Investment Funds for the district modality in support to the farming world, the new EU Regulation for rural development focuses its attention on different forms of public and private partnerships, aimed at promoting the local cooperation in several fields, from the development of the short spinnerets to the innovation in agro-food and forest sectors, from rural tourism to the sustainable supplying of biomasses, etc. Moreover, in the territories where it comes out from a serious bottom-up process of involvement of local actors, the QAFD or the RD could become the pivot of the management and administrative integration between the planning and project moments of the Common Strategic Framework 2014-2020. Also in an experimental way and on the basis of the agreement of the local stakeholders, it could aspire to a role of direction of the interventions carried out in the agro-food and rural field. 


\section{References}

[1] E. Basile and C. Cecchi: Differenziazione e integrazione nell'economia rurale. In: Rivista di Economia Agraria. 52 (1997), pp. 3-27

[2] E. Basile: La ruralità nella informalizzazione dell'economia. In: Rivista di Economia Agraria. 54 (1999), pp. 127-140

[3] P. Careri, E. D'Angelillo and C. Marcianò: I Distretti Rurali ed Agroalimentari di Qualità in Calabria. In Marcianò C. (Ed.): Governance rurali in Calabria, Mediterranean University of Reggio Calabria, Reggio Calabria University Press, (2013), pp. 311-333

[4] D. Toccaceli: Dai Distretti alle Reti? I distretti in agricoltura nell'interpretazione delle Regioni e le prospettive verso il 2020, Rete Rurale Nazionale, Roma, (2012)

[5] EU: Regulation No 1305/2013 of the European Parliament and of the Council, on support for rural development by the European Agricultural Fund for Rural Development (EAFRD), (2013)

[6] Unioncamere - Istituto Tagliacarne: I Distretti Rurali ed Agroalimentari di Qualità in Italia: una prima mappatura nazionale, Roma (2004)

[7] C. Brasili: I sistemi locali agroalimentari: un caso di studio. In: R. Fanfani e G. Galizzi (a cura di): Il sistema agro-alimentare dell'Emilia-Romagna, Rapporto (1999), Ed. Franco Angeli (2000)

[8] F. Sforzi: L'identificazione spaziale. In: G. Becattini (ed.): Mercato e forze locali: il distretto industriale, Il Mulino (1987)

[9] A. Pacciani: La Maremma Distretto Rurale, un nuovo modello di sviluppo nella consapevolezza della propria identità, Ed. Il mio Amico, Grosseto (2003)

[10] J.S. Coleman: Foundation of Social Theory, Cambridge, MA, Harvard University Press (1990)

[11] M.S. Granovetter: The Strenght of Weak Ties, Amer (2009)

[12] A. Marshall: Principles of Economics, Italian Edition, Utet (1972)

[13] R. Cagliero and G. Pastorino: Il ruolo della politica distrettuale nello sviluppo rurale, Agriregionieuropa, 3, (2005), pp. 1-4

[14] T. Calabrò, A. I. De Luca, G. Gulisano and C. Marcianò: The Rural Governance System in Leader Plus: the Application of an Integrated Planning Methodology in Calabria (South Italy), New Medit, 3, (2005), pp. 38-46

[15] C. Marcianò and M. Palladino: La pianificazione integrata in un'area calabrese nell'ottica di una rete di affiliazione. In: C. Marcianò (Ed.): Governance rurali in Calabria, Università degli Studi Mediterranea di Reggio Calabria, Centro Stampa di Ateneo, (2013) 